\title{
Infecção pelo Papilomavirus Humano durante a Gravidez: Relação com Achados Citológicos
}

\author{
Human Papillomavirus Infection in Pregnancy: Relationship with Cytological Findings \\ Eddie Fernando Candido Murta, Maria Azniv Hazarabedian de Souza \\ Sheila Jorge Adad, Edward Araújo Júnior
}

\section{RESUMO}

Objetivo: estudar um grupo de mulheres grávidas com infecção pelo papilomavírus humano (HPV), analisando a faixa etária, a idade gestacional, o número de gestações e os achados citológicos.

Métodos: no periodo de julho de 1993 a dezembro de 1998, 245 gestantes atendidas em nosso serviço apresentavam alterações citológicas compativeis com infecção pelo HPV, associados ou não à neoplasia intra-epitelial cervical (NIC) grau I. Foram colhidos dados clínicos relacionados à idade, periodo gestacional (primeira ou segunda metade), número de gestações e achado citológico de Trichomonas vaginalis, Candida $s p$. e clue cells. O grupo controle foi constituido por 386 pacientes gestantes atendidas no mesmo periodo e sem achados citológicos de infecção pelo HPV. Na análise estatística utilizou-se o teste do $\chi^{2}$ (quiquadrado) com correção de Yates com nivel de significância menor que 0,05.

Resultados: a infecção pelo HPV foi mais freqüente nas grávidas com idade inferior a 20 anos $(45,3 \%$ versus $28,2 \%, p<0,001)$. O achado citológico mais freqüente nas grávidas com infecção pelo $H P V$, comparando-se com o controle, foi o de clue cells $(21,6 \%$ versus $12,4 \%$, $p<0,02)$. O achado de clue cells foi mais freqüente nas gestantes com HPV com idade superior a 20 anos e na segunda metade da gestação (27\% versus $12,2 \%, p<0,01)$. A diferença quanto ao número de gestações anteriores não foi significativa.

Conclusões: para o grupo estudado, a infecção pelo HPV foi mais freqüente em grávidas com idade inferior a 20 anos. Os achados citológicos de clue cells e de HPV foram mais freqüentes nas mulheres grávidas com idade superior a 20 anos e na segunda metade da gestação.

PALAVRAS-CHAVE: Papilomavirus humano. Clue cells. Citologia cérvico-vaginal. Infecções na gravidez.

\section{Introdução}

A maior freqüência de infeção por papilomavirus humano (HPV) em gestantes em relação a não-gestantes sugere que a gravidez é um fator de risco para infecção pelo HPV ${ }^{1}$. Durante a gestação ocorreria a expressão clínica máxima da infecção genital pelo HPV, com rápida regressão durante o puerpério $^{2}$. Este aumento de incidência

Disciplina de Ginecologia e Obstetrícia da Faculdade de Medicina do Triângulo Mineiro, Uberaba - MG, Brasil Correspondência

Eddie Fernando Candido Murta

Av. Alfén Paixão, 170, Apto 202 - Mercês

38060-230 - Uberaba - MG

Telefone: 55213433185326 - Fax: 55213433185342

e-mail:eddiemurta@mednet.com.br pode ser explicado pela modulação imunológica ou pela influência de fatores hormonais durante a gestação ${ }^{3}$. No entanto, alguns autores encontraram uma freqüência de infecção pelo HPV semelhante em gestantes e não-gestantes ${ }^{4,5}$.

Em relação à idade gestacional, Morrison et al. ${ }^{6}$ demonstraram que a infecção é mais freqüente após 12 semanas de gestação. Meisels ${ }^{7}$ relatou que a infecção por HPV é mais comum na segunda metade da gestação. Entretanto, Chang-Claude et al. ${ }^{4}$ demonstraram que a incidência da infecção pelo HPV é independente da idade gestacional.

Em relação à paridade, Gopalkrishna et al. ${ }^{8}$ relataram aumento da incidência desta infecção com aumento do número de gestações, porém Morrison et $a .^{6}$ demonstraram que a infecção é 
mais freqüente em mulheres com menos de 3 gestações.

Muitos processos infecciosos cérvico-vaginais são decorrentes de um desequilíbrio da flora, como ocorre na gravidez ${ }^{9}$. Voog et al. ${ }^{10}$, estudando a presença de Candida sp por meio de cultura, encontraram nas pacientes com positividade de DNA-HPV uma prevalência de $26 \%$ comparado a $16 \%$ das pacientes negativas. Outros trabalhos não demonstraram que a história prévia de doença sexualmente transmissivel é um fator de risco isolado para infecção por HPV, com exceção da infecção pela Chlamydia trachomatis ${ }^{11}$. Murta et al. ${ }^{12}$ demonstraram que a Gardnerella vaginalis é o agente mais freqüente nas pacientes não-gestantes com sinais citológicos de infecção por HPV.

A infecção pelo HPV na gestação têm sido estudada e apresenta resultados discordantes. Poucos trabalhos têm se referido a achados citológicos e a presença da infecção pelo HPV em grávidas. Portanto, o objetivo deste trabalho é avaliar um grupo de mulheres grávidas com infecção pelo HPV, analisando a faixa etária de maior freqüência, a possivel influência da idade gestacional e do número de gestações e os achados citológicos.

\section{Pacientes e Métodos}

Trata-se de um estudo retrospectivo dos casos atendidos entre julho de 1993 e dezembro de 1998, em um centro público de referência terciária. Verificou-se que 245 pacientes gestantes apresentavam, na citologia (coleta tríplice: endocervical, ectocervical e vaginal), infecção por HPV de acordo com os critérios de Schneider et al. ${ }^{13}$, associada ou não a neoplasia intra-epitelial cervical (NIC) grau I. As pacientes com diagnóstico de NIC II ou NIC III foram excluídas desta análise.

Foram colhidos dados clínicos relacionados a idade, período gestacional (primeira ou segunda metade), número de gestações e achado citológico de Trichomonas vaginalis, Candida sp e clue cells. Para a determinação da idade gestacional foram utilizadas: data da última menstruação, altura uterina e ultra-sonografia. Os critérios de Schneider et al. ${ }^{13}$ são baseados na presença de coilocitose clássica ou, pelo menos, na presença de seis dos nove critérios não-clássicos, quais sejam: coilocitose leve, disqueratose leve, clareamento citoplasmático, grânulos queratohialinos, estriação citoplasmática, células paraqueratóticas, hipercromasia celular, bi ou multinucleação e halo perinuclear.

O grupo controle foi constituído por todas as gestantes sem sinais citológicos de infecção pelo HPV atendidas de agosto a outubro de 1993 e em janeiro e fevereiro dos anos de 1996 e 1998 (n = 386). Em ambos os grupos foi avaliada a presença dos mesmos microrganismos referidos anteriormente. $\mathrm{Na}$ análise estatística utilizou-se o teste do $\chi^{2}$ (qui-quadrado) com correção de Yates, com nivel de significância menor que 0,05.

\section{Resultados}

Observa-se na Tabela 1 que os sinais citológicos de infecção por HPV são mais freqüentes nas mulheres grávidas com idade inferior a 20 anos $(44,5 \%$ versus $28,5 \%, p<0,0001)$. Das gestantes com sinais citológicos da infecção pelo HPV, $129(52,6 \%)$ estavam na primeira metade da gestação contra $163(42,2 \%)$ do grupo controle $(\mathrm{p}<0,05)$.

Tabela 1 - Comparação da faixa etária, idade gestacional e do número de gestações entre 0 grupo de mulheres grávidas com diagnóstico citológico de infecção por HPV $(\mathrm{HPV}+, n=245)$ e o grupo de mulheres grávidas sem sinais citológicos de infecção por HPV (HPV - $n=386)$.

\begin{tabular}{|c|c|c|c|c|}
\hline \multirow[t]{2}{*}{ Parâmetros avaliados } & \multicolumn{2}{|c|}{ HPV + } & \multicolumn{2}{|c|}{ HPV - } \\
\hline & $\mathrm{n}$ & $\%$ & $\mathrm{n}$ & $\%$ \\
\hline \multicolumn{5}{|l|}{ Idade (anos) } \\
\hline$<20^{*}$ & 109 & 44,5 & 110 & 28,5 \\
\hline$\geq 20$ & 136 & 55,5 & 276 & 71,5 \\
\hline \multicolumn{5}{|l|}{ Semanas de gestação } \\
\hline $1-20$ ** & 129 & 52,6 & 163 & 42,2 \\
\hline $21-42$ & 116 & 47,4 & 223 & 57,8 \\
\hline \multicolumn{5}{|l|}{ Número de gestações } \\
\hline$\leq 3$ & 199 & 81,2 & 314 & 81,3 \\
\hline$\geq 4$ & 46 & 18,8 & 72 & 18,7 \\
\hline
\end{tabular}

Na Tabela 2, observa-se a maior freqüência de clue cells $(21,6 \%$ versus $12,4 \%, \mathrm{p}<0,001)$ e a menor freqüência de Candida sp. $(20 \%$ versus $29,8 \%, p<0,05)$ nas mulheres grávidas que apresentam sinais citológicos de infecção por HPV.

$\mathrm{O}$ achado de clue cells em relação à idade das pacientes e da gestação está na Tabela 3. A presença de clue cells foi mais freqüente nas gestantes com idade inferior a 20 anos e até a $20^{a}$ semana de gestação, com $22,4 \%$ dos casos. Nas Tabelas 4 e 5 está a distribuição dos achados de clue cells em relação à presença de infecção pelo HPV, idades das mulheres e da gestação. As ges- 
tantes com idade superior a 20 anos na primeira metade da gestação e com infecção pelo HPV têm maior freqüência de achado de clue cells que o controle $(24,6 \%$ versus $15,2 \%$, Tabela 4$)$. Observa-se que o achado de clue cells é mais freqüente nas gestantes com idade superior a 20 anos na segunda metade de gestação e com infecção com HPV $(27 \%$ versus $12,2 \%, \mathrm{p}<0,01$, Tabela 5 ).

Tabela 2 - Comparação dos achados citológicos entre o grupo de mulheres grávidas com diagnóstico citológico de infecção por HPV (HPV+) e o grupo de mulheres grávidas sem sinais citológicos de infecção por HPV (HPV-).

\begin{tabular}{lrrrr}
\hline Achados citológicos & \multicolumn{2}{c}{ HPV+ } & \multicolumn{2}{c}{ HPV- } \\
& n & \multicolumn{1}{c}{$\%$} & \multicolumn{1}{c}{ n } & $\%$ \\
\hline Trichomonas vaginalis & 6 & 2,5 & 20 & 5,2 \\
Candida sp* & 49 & 20,0 & 115 & 29,8 \\
Clue cells* & 53 & 21,6 & 48 & 12,4 \\
Trichomonas vaginalis + Candida sp & 1 & 0,4 & 4 & 1,0 \\
Clue cells + Candida sp & 4 & 1,6 & 9 & 2,3 \\
Trichomonas vaginalis + clue cells & 1 & 0,4 & 1 & 0,3 \\
Trichomonas vaginalis + Candida sp & & & & \\
+ clue cells & - & - & 1 & 0,3 \\
Sem alterações & 131 & 53,5 & 188 & 48,7 \\
Total & 245 & 100 & 386 & 100 \\
\hline
\end{tabular}

${ }^{*} p<0,01 ;{ }^{* *} p<0,001$

Tabela 3 - Distribuição da idade das mulheres e da idade gestacional em relação ao achado de clue cells $(\mathrm{CC}+)$.

\begin{tabular}{|c|c|c|c|c|c|c|c|c|c|}
\hline & \multicolumn{4}{|c|}{$<20$ semanas } & \multicolumn{4}{|c|}{$\geq 20$ semanas } & \multirow[t]{3}{*}{ Total } \\
\hline & \multicolumn{2}{|c|}{$<20$ anos } & \multicolumn{2}{|c|}{$\geq 20$ anos } & \multicolumn{2}{|c|}{$<20$ anos } & \multicolumn{2}{|c|}{$\geq 20$ anos } & \\
\hline & $n$ & $\%$ & $\mathrm{n}$ & $\%$ & $n$ & $\%$ & $n$ & $\%$ & \\
\hline $\mathrm{CC}+$ & 24 & 22,4 & 35 & 18,9 & 21 & 18,7 & 37 & 16,3 & 117 \\
\hline CC- & 83 & 77,6 & 150 & 81,1 & 91 & 81,3 & 190 & 83,7 & 514 \\
\hline Total & 107 & 100 & 185 & 100 & 112 & 100 & 227 & 100 & 631 \\
\hline
\end{tabular}

p: não significante

Tabela 4 - Comparação da idade das pacientes e dos achados de clue cells (CC+) no exame citológico entre o grupo de mulheres grávidas com diagnóstico citológico de infecção por HPV $(\mathrm{HPV}+)$ e o grupo de mulheres grávidas sem sinais citológicos de infecção por HPV (HPV-) com menos de 20 semanas de gestação.

\begin{tabular}{ccccccccccrr}
\hline & \multicolumn{4}{c}{ HPV+ } & \multicolumn{4}{c}{ HPV- } & Total \\
& $<20$ & anos & $\geq 20$ & anos & \multicolumn{3}{c}{$<20$} & anos & $\geq 20$ & anos & \\
& $\mathbf{n}$ & $\%$ & $\mathbf{n}$ & $\%$ & $\mathbf{n}$ & $\%$ & $\mathbf{n}$ & $\%$ & \\
\hline CC+ & 11 & 19,6 & 18 & 24,6 & 13 & 25,5 & 17 & 15,2 & 59 \\
CC- & 45 & 80,4 & 55 & 75,4 & 38 & 74,5 & 95 & 84,8 & 233 \\
Total & 56 & 100 & 73 & 100 & 51 & 100 & 112 & 100 & 292 \\
\hline
\end{tabular}

p: não-significante
Tabela 5 - Comparação da idade das pacientes e dos achados de clue cells (CC+) no exame citológico entre o grupo de mulheres grávidas com diagnóstico citológico de infecção por HPV (HPV+) e o grupo de mulheres grávidas sem sinais citológicos de infecção por HPV (HPV-) com mais de 21 semanas de gestação.

\begin{tabular}{|c|c|c|c|c|c|c|c|c|c|}
\hline & \multicolumn{4}{|c|}{ HPV+ } & \multicolumn{4}{|c|}{ HPV- } & \multirow[t]{3}{*}{ Total } \\
\hline & \multicolumn{2}{|c|}{$<20$ anos } & \multicolumn{2}{|c|}{$\geq 20$ anos * } & \multicolumn{2}{|c|}{$<20$ anos } & \multicolumn{2}{|c|}{$\geq 20$ anos } & \\
\hline & $n$ & $\%$ & $\mathrm{n}$ & $\%$ & $\mathrm{n}$ & $\%$ & $\mathrm{n}$ & $\%$ & \\
\hline $\mathrm{CC}+$ & 13 & 24,5 & 17 & 27,0 & 8 & 15,6 & 20 & 12,2 & 58 \\
\hline CC- & 40 & 75,5 & 46 & 73,0 & 51 & 84,6 & 144 & 87,8 & 281 \\
\hline Total & 53 & 100 & 63 & 100 & 59 & 100 & 164 & 100 & 339 \\
\hline
\end{tabular}

* $p<0,01$, comparado com o grupo controle.

\section{Discussão}

Observamos que houve maior freqüência de diagnóstico citológico de infecção por HPV nas pacientes grávidas mais jovens. A freqüência de infecção por HPV é maior nas pacientes jovens em relação às mulheres mais velhas, independente da presença ou não de gravidez $z^{4,14,15}$. A explicação para a maior incidência nas mulheres jovens pode ser pela maior exposição do epitélio colunar da endocérvice, que teria mais suscetibilidade a agentes físico-químicos e biológicos ${ }^{16}$. Entretanto, Karlsson et al. ${ }^{17}$ não encontraram relação entre ectopia e infecção por HPV.

Em relação à idade gestacional, permanece muita discordância sobre o periodo no qual a infecção por HPV seria mais prevalente. Meisels ${ }^{7}$, analisando 29.153 citologias de mulheres grávidas, encontrou alterações citológicas compativeis com infecção por HPV em 107 (7,3\%) de 1.459 citologias obtidas na segunda metade da gestação, versus 850 (3\%) de 27.694 citologias na primeira metade de gestação. Gopalkrishna et al. ${ }^{8}$ estudando material citológico de mulheres grávidas por meio da hibridização do DNA-HPV, observaram positividade para o HPV em 31 (50\%) de 62 mulheres na segunda metade da gestação e em $13(34,2 \%)$ das 38 mulheres grávidas com idade gestacional inferior a 20 semanas. Estas diferenças podem ser explicadas pela diminuição de função do sistema de defesa imunológica, devida aos altos níveis de estrógeno e progesterona, o que pode interferir no sistema regulatório da replicação viral ${ }^{18}$.

Outros autores não encontraram diferença em relação ao período da gestação em que seria mais prevalente a infecção por HPV ${ }^{4,15}$. ChangClaude et $\mathrm{al.}^{4}$, em um estudo que incluiu 108 mulheres grávidas com uso de hibridização do DNA-HPV, encontraram positividade para DNAHPV em $4(7,7 \%)$ de 52 gestantes no primeiro trimestre, em duas (2\%) de 101 no segundo trimestre e em $7(5,8 \%)$ de 121 no terceiro trimestre. Murta et al. ${ }^{15}$, estudando 93 mulheres grávidas 
com sinais citológicos de infecção por HPV, demonstraram que $49(52,7 \%)$ estavam na primeira metade da gestação e $44(47,3 \%)$ na segunda metade. Por outro lado, de Roda Husman et al. ${ }^{19}$, estudando a prevalência de HPV com o uso de um método semiquantitativo por PCR de detecção do HPV 16/ 18 em mulheres gestantes com citologia normal, demonstraram que não houve diferença estatística de achados entre a primeira metade e a segunda metade da gestação. Entretanto, na primeira metade da gestação foi encontrado maior número de cópias virais em relação à segunda metade.

Em relação ao número de gestações anteriores, nossos resultados mostraram uma diminuição da freqüência da infecção por HPV com a maior paridade, mas sem significância estatística. Estes achados estão de acordo com os descritos por Murta et al. ${ }^{15}$ e Morrison et al. ${ }^{6}$. Estes dados, no entanto, divergem dos descritos por Gopalkrishina et al. ${ }^{8}$, que demonstraram maior freqüência da infecção pelo vírus com o aumento do número de gestações. Este achado se justificaria pelo início precoce da vida reprodutiva. Outro fator é a multiparidade com curto intervalo entre os partos. Isto, segundo os autores, poderia facilitar a replicação do vírus com maior freqüência e, conseqüentemente, perpetuando a infecção.

A presença de co-infecções genitais, transmitidas sexualmente ou não, pode ser de importância para a aparecimento dos condilomas genitais. Isto ocorre, provavelmente, devido a um aumento da umidade do meio vaginal, pelo aumento da secreção vaginal ${ }^{20}$. É também sabido que a gestação gera um desequilíbrio na flora vaginal, favorecendo o desenvolvimento tanto do HPV quanto de outros agentes infecciosos ${ }^{9}$. Carne e Dockerty ${ }^{21}$ observaram a presença de co-infecções em 60 de 179 homens (34\%) e em 91 de 168 mulheres (54\%), sendo que em $80 \%$ dos homens e $51 \%$ das mulheres eram doença sexualmente transmissivel (DST). Entretanto, alguns trabalhos não consideram história prévia de DST como fator de risco isolado para o HPV, com exceção da infecção por Chlamydia trachomatis ${ }^{11}$. Em nosso trabalho não analisamos a incidência de Chlamydia, por não ser a citologia o método mais indicado para seu diagnóstico, pela sensibilidade baixa ${ }^{22}$.

A freqüência de Candida $\mathrm{sp}$ em gestantes sem sinais citológicos de infeção por HPV foi de $29,8 \%$. A gravidez é um fator predisponente para a presença deste microrganismo ${ }^{23}$, mas nas mulheres que apresentam a infecção por HPV, a incidência está diminuída.

A incidência de vaginose bacteriana nas mulheres varia de $4 \%$ a $64 \%$, dependendo da população estudada ${ }^{24}$. Nossos resultados, baseados na presença de clue cells em exame citológico de grávidas, mostraram uma freqüência de $12,4 \%$ nas mulheres sem infecção por HPV contra $21,6 \%$ das que apre- sentaram infecção por HPV. Se há uma interação sinérgica entre a infecção pelo HPV e as bactérias que levam ao achado de clue cells, isto poderá ser estabelecido com a realização de novas pesquisas. A vaginose bacteriana, juntamente com a infecção pelo HPV, está associada ao desenvolvimento da $\mathrm{NIC}^{25}$. Ressaltamos que o achado de clue cells é mais freqüente nas gestantes com infecção pelo HPV com mais de 20 anos de idade e na segunda metade da gestação, em comparação ao grupo controle.

Embora nosso estudo tenha utilizado critérios citológicos e não testes diagnósticos específicos, o exame citológico é largamente usado na prática clínica e pode trazer subsídios para propostas de novas pesquisas. A utilização dos critérios de Schneider et al. ${ }^{13}$ em citologia triplice pode identificar $84 \%$ das mulheres positivas para HPV e $92 \%$ das negativas, quando comparada com teste de hibridização do DNA-HPV.

Concluímos que o diagnóstico citológico de infecção por HPV apresentando ou não NIC I, predominou em gestantes com idade inferior a 20 anos. A maior porcentagem de mulheres com associação de infecção pelo HPV e clue cells encontrada neste trabalho merece investigação utilizando-se testes microbiológicos mais sensiveis.

\section{SUMMARY}

Purpose: to evaluate a group of pregnant women with human papillomavirus (HPV) infection, analyzing age, gestational age, number of gestations and cytological findings.

Methods: in the period from July 1993 to December 1998, 245 pregnant patients seen in our service presented cytological alterations compatible with HPV infection, associated or not with cervical intraepithelial neoplasia (CIN) grade 1. Clinical data were related to age, gestational period (first or second half), number of gestations and cytological finding of Trichomonas vaginalis, Candida sp and clue cells. The control group consisted of 386 pregnant patients seen during the same period and without cytological signs of HPV infection. In the statistical analysis, $\chi^{2}$ (chisquare) test was used with Yates correction and a significance level lower than 0.05.

Results: HPV infection was more frequent among pregnant women younger than 20 years old $(45.3 \%$ versus $28.2 \%$, $p<0.001)$. The most frequent cytological finding, among the pregnant women with HPV infection, was the presence of clue cells, compared to the controls $(21.6 \%$ versus $12.4 \%$, $p<0.02)$. Clue cells were more frequent in pregnant women with HPV infection in the second half of gestation and older than 20 years $(27 \%$ versus $12.2 \%, p<0,01)$. The difference regarding number of gestations was not significant.

Conclusion: HPV infection was more frequent among pregnant women younger than 20 years old. Clue cells and HPV were the most frequent cytological findings in pregnant women older than 20 years and in the second half of gestation. 
KEY WORDS: Human papillomavirus. Clue cells. Cervicovaginal smear. Infection during pregnancy.

\section{Referências}

1. Fife KH, Katz BP, Roush J, Handy VD, Brown DR, Hansell R. Cancer-associated human papillomavirus types are selectively increased in the cervix of women in the first trimester of pregnancy. Am J Obstet Gynecol 1996; 174:1487-93.

2. Garry R, Jones R. Relationship between cervical condylomata, pregnancy and subclinical papillomavirus infection. J Reprod Med 1985; 30:393-9.

3. Kiviat NB, Koustsky LA, Critchlow CW, et al. Comparison of Southern transfer hybridization and dot filter hybridization for detection of cervical human papillomavirus infection with types 6,11 , 16, 18, 31, 33 and 35. Am J Clin Pathol 1990; 94:561-5.

4. Chang-Claude J, Schneider A, Smith E, Blettner M, Wahrendorf J, Turek L. Longitudinal study of the effects of pregnancy and other factors on detection of HPV. Gynecol Oncol 1996; 60:355-62.

5. Smith EM, Johnson SR, Jiang D, et al. The association between pregnancy and human papillomavirus prevalence. Cancer Detect Prev $1991 ; 15: 397-402$.

6. Morrison EAB, Gammon MD, Goldberg GL, Vermund $\mathrm{SH}$, Burk RD. Pregnancy and cervical infection with human papillomaviruses. Int J Gynaecol Obstet 1996; 54:125-30.

7. Meisels A. Cytologic diagnosis of human papillomavirus: influence of age and pregnancy stage. Acta Cytol 1992; 36:480-2.

8. Gopalkrishna V, Murthy NS, Sharma JK, et al. Increased human papillomavirus infection with the increasing number of pregnancies in Indian women. J Infect Dis 1995; 171:254-5.

9. Faro S. Bacterial vaginitis. Clin Obstet Gynecol 1991; 34:582-6.

10.Voog E, Bolmstedt A, Olofsson S, Ryd W, Lowhagen GB. Human papillomavirus infection among women attending an STD clinic correlated to reason for attending, presence of clinical signs, concomitant infections and abnormal cytology. Acta Derm Venereol 1995; 75:75-8.

11.Gutman LT, Herman-Giddens ME, Phelps WC. Transmission of human genital papillomavirus disease: comparison of data from adults and children. Pediatrics 1993; 91:31-8.

12.Murta EFC, Souza MAH, Araújo Júnior E, Adad SJ. Incidence of Gardnerella vaginalis, Candida sp., and human papillomavirus in cytological smears. São Paulo Med J 2000; 118:105-8.
13. Schneider A, Meinhardt G, De-Villiers EM, Gissmann L. Sensitivity of the cytologic diagnosis of cervical condyloma in comparison with HPVDNA hybridization studies. Diagn Cytopathol 1987; 3:250-5.

14. Murta EFC, Souza MAH, Lombardi W, Borges LS. Aspectos epidemiológicos da infecção pelo papilomavirus humano. J Bras Ginecol 1997; 107:95-9.

15.Murta EFC, Souza MAH, Adad SJ, Pires RA, Matthes AGZ. Influência da idade materna do periodo gestacional e do número de gestações na infecção pelo papilomavirus humano. Rev Bras Ginecol Obstet 1998; 20:33-5.

16.Koutsky LA, Galloway DA, Holmes KK. Epidemiology of genital human papillomavirus infection. Epidemiol Rev 1988; 10:122-63.

17.Karlsson R, Jonsson M, Edlund K, et al. Lifetime number of partners as the only independent risk factor for human papillomavirus infection: a population based study. Sex Transm Dis 1995; 22:119-27.

18.Ponta H, Kennedy N, Skroch P, Hynes NE, Groner $B$. The hormonal response region in the mouse mammary tumor virus long terminal repeat can be dissociated from the proviral promoter and has enhancer properties. Proc Natl Acad Sci USA 1985; 82:1020-4.

19.de Roda Husman AM, Walboomers JM, Hopman E, et al. HPV prevalence in cytomorphologically normal cervical scrapes of pregnant women as determined by PCR: the age-related pattern. J Med Virol 1995; 46:97-102.

20. Oriel JD. The natural history of genital warts. Br J Vener Dis $1971 ; 47: 1-13$.

21.Carne CA, Dockerty G. Genital warts: need to screen for coinfection. BMJ 1990; 300:459.

22.Rettig PJ. Perinatal infections with Chlamydia trachomatis. Clin Perinatol 1988; 15:321-50.

23. Sobel JD. Candidal vulvovaginitis. Clin Obstet Gynecol 1993; 36:153-65.

24.Thomason JL, Gelbart SM, Scaglione NJ. Bacterial vaginosis: current review with indications for asymptomatic therapy. Am J Obstet Gynecol 1991; 165:1210-7.

25.Platz-Christensen JJ, Sundstrom E, Larsson PG. Bacterial vaginosis and cervical intraepithelial neoplasia. Acta Obstet Gynecol Scand 1994; 73:586-8.

\section{Agradecimentos}

Os autores agradecem ao Serviço de Citopatologia da Faculdade de Medicina do Triângulo Mineiro e ao Conselho Nacional de Desenvolvimento Científico e Tecnológico (CNPq) pelo apoio financeiro. 